\title{
Triangular retractor facilitates minimally invasive lobectomy
}

\author{
Todd L. Demmy, MD, Chukwumere E. Nwogu, MD, and Marc S. Sussman, MD, Buffalo, NY
}

V ideo-assisted thoracic surgery (VATS) lobectomies are feasible, preferred at certain centers, and gaining in popularity. ${ }^{1}$ Yet some VATS maneuvers remain difficult or clumsy compared with open techniques, such as lifting the partially dissected lobe by hand away from the hilum to find remaining connections.

\section{Technique}

Diamond-flex triangular retractor system (Snowden-Pencer, Tucker, Ga) devices begin as flexible, snakelike, hollow, 5-mm metal tubes composed of small individual sections threaded over internal tension cables anchored to the tips. The individual tubular sections are cut obliquely so that when the internal metal cables are tightened, the retractors conform into triangular shapes. Typically, each retractor is inserted while loose and flexible though a $5-\mathrm{mm}$ port and then conformed within the open abdominal cavity to retract the liver or other structures.

This tool controls nearly freed upper lobe lung specimens as well. After most of the incomplete fissure tissue and pulmonary vascular attachments have been divided, a Diamond-flex retractor can be passed through a working port and curled around the lung specimen. By using an anterior working port, the device will slide naturally along the anterior thoracic apex and then loop inferiorly around the base of the upper lobe. Then the retractor is conformed by tightening the screw in the handle with its tip in view so that it does not curl into delicate hilar structures. Given its relatively small diameter, additional tools can be passed through the same 10-mm working incision.

This instrument is manufactured in straight or angulated conformations of different lengths. We prefer a straight 60 -mm device, but the best size is selected according to the thoracic cavity and lung size. Figure 1 demonstrates the control of the right upper lobe afforded by this method. In addition, a linear cutting stapler is depicted ready to complete the lobectomy by dividing the right upper lobe bronchus.

Once the specimen has been freed from its attachments, extracting it can be difficult. This maneuver is facilitated by inserting the nylon sac (Lapsac; $5 \times 8$ in; Cook Group, Inc, Bloomington,

From the Department of Thoracic Surgery, Roswell Park Cancer Institute, Buffalo, NY.

Received for publication Jan 4, 2005; accepted for publication Feb 8, 2005.

Address for reprints: Todd L. Demmy, MD, Roswell Park Cancer Institute, Elm \& Carlton Sts, Buffalo, NY 14263 (E-mail: Todd.Demmy@ roswellpark.org).

J Thorac Cardiovasc Surg 2005;129:1454-5

$0022-5223 / \$ 30.00$

Copyright $\odot 2005$ by The American Association for Thoracic Surgery doi:10.1016/j.jtcvs.2005.02.019

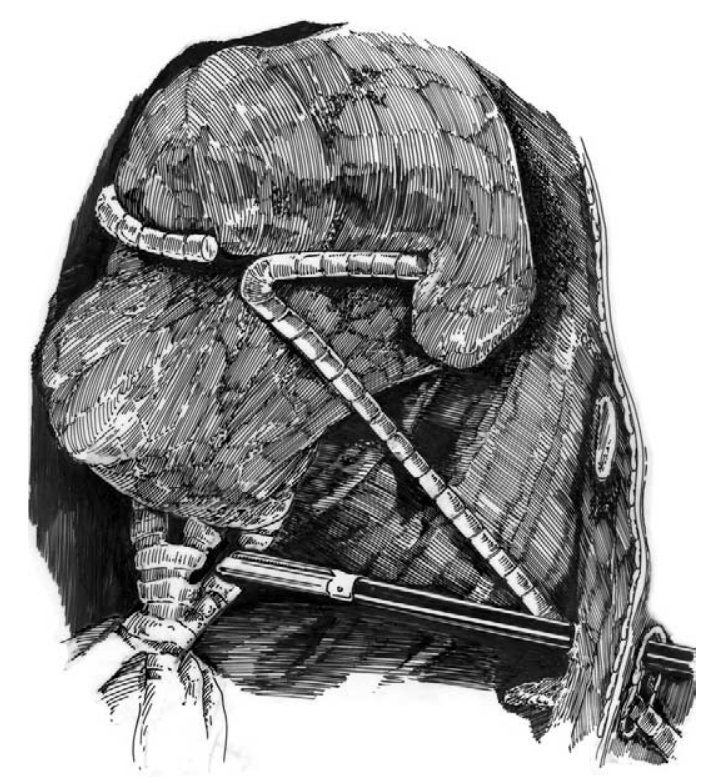

Figure 1. Retractor control of the upper lobe.

Ind) through the access incision and controlling one portion of the sac externally. Additional points of fixation are needed to open the sac. Although this can be accomplished with instruments or sutures, the above retractor creates a base to yield a nice triangular opening. If needed, saline instillation or the retractor can help open the rest of the empty sac.

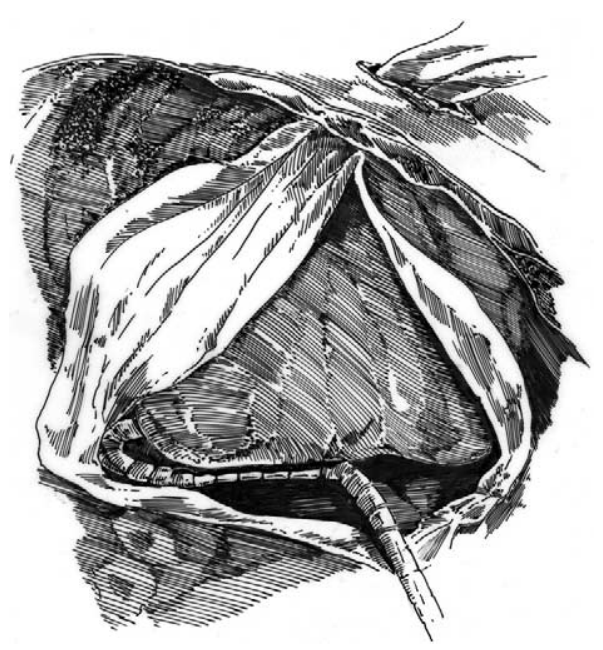

Figure 2. Control of the sac opening. 
Once the opening is controlled, it is easy to place a grasping instrument through the same working port as the triangular retractor to push the isolated lobe into the specimen extraction sac. Once its lead point is inserted, another instrument placed through the access incision maintains the specimen's forward progress so that the endoscopic grasper can gain a fresh hold on the tissue. With the cooperative use of these instruments, the lobe is inserted quickly. Figure 2 depicts the sac held open just after lung insertion.

\section{Discussion}

Thoracic surgeons periodically reevaluate their interests in complex VATS operations as technology advances. ${ }^{2}$ Recent enhancements in video equipment aid exposure, and new specialized tools reduce operative times, making these cases more relevant to a busy surgical practice.

Upper lobe tissue often flops onto the hilum. This requires a lot of camera shifting and lung rolling to ensure complete dissection and thereby prevent inadvertent avulsion of an aber- rant pulmonary artery branch. The described retraction method allows lifting the lung toward the lateral chest wall so that residual hilar connections can be viewed. Some authors advocate dividing the bronchus first to gain this exposure, but we prefer technology that allows us to approximate our traditional open methods.

Although introducing bulky lobes into specimen extraction sacs can be tedious, this technical modification reduced a variable 5- to 20-minute process into a routine step lasting 2 to 3 minutes. The study of other minimally invasive disciplines might yield additional useful instrument adaptations.

\section{References}

1. Swanson SJ, Herndon J, D’Amico TA, Demmy TL, McKenna R Jr, Green M, et al. Results of CALGB 39802: feasibility of video-assisted thoracic surgery (VATS) lobectomy for early stage lung cancer [abstract]. Proc Am Soc Clin Oncol. 2002;21:290a.

2. Demmy TL, Curtis JJ, Boley TM, Walls JT, Nawarawong W, Schmaltz RA. Diagnostic and therapeutic thoracoscopy: lessons from the learning curve. Am J Surg. 1993;166:696-700.

\title{
Successful subtotal tracheal replacement (using a skin/omental graft) for dehiscence after a resection for thyroid cancer
}

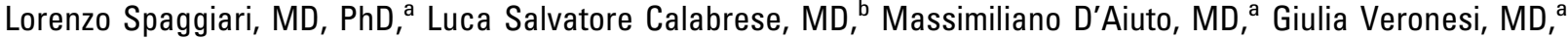 \\ Domenico Galetta, MD, ${ }^{a}$ Marco Venturino, MD, ${ }^{\mathrm{c}}$ and Fausto Chiesa, MD, ${ }^{\mathrm{b}}$ Milan, Italy
}

T racheal resection is still one of the greatest challenges in the treatment of tracheal tumors. ${ }^{1}$ The maximum amount of trachea that can be resected during resection-anastomosis is around $50 \%$, but, when a larger resection is required, the risk of postoperative dehiscence increases, followed by a very elevated risk of postoperative death.

We report on our experience with treating a tracheal anastomotic dehiscence that developed after an extended tracheal resection was performed for a thyroid tumor relapse. The technique used to repair the dehiscence, a composite skin/omental/ muscle graft, permitted restoration of tracheal continuity and of a normal respiratory function.

\footnotetext{
From the Division of Thoracic Surgery, ${ }^{\mathrm{a}}$ Head and Neck Division, ${ }^{\mathrm{b}}$ and Division of Anesthesiology and Intensive Care Unit, ${ }^{\mathrm{c}}$ European Institute of Oncology, Milan, Italy.

Received for publication Oct 2, 2004; accepted for publication Nov 4, 2004.

Address for reprints: Lorenzo Spaggiari, MD, PhD, Division of Thoracic Surgery, European Institute of Oncology, Via Ripamonti, 435, 20141 Milan, Italy (E-mail: lorenzo.spaggiari@ieo.it).

J Thorac Cardiovasc Surg 2005;129:1455-6

$0022-5223 / \$ 30.00$

Copyright $\odot 2005$ by The American Association for Thoracic Surgery

doi:10.1016/j.jtcvs.2004.11.010
}

\section{Clinical Summary}

In May 2001, a 37-year-old man underwent thyroidectomy for medullary carcinoma of the thyroid at another institution. In May 2002, he developed a relapse with tracheal infiltration and was admitted to our institute in July 2002 for an extended resection of the trachea. A double transmanubrial approach was used. $^{2}$ After an extensive tracheal devascularization, a $5.5-\mathrm{cm}$ long tracheal resection was performed. The tumor $(9.2 \mathrm{~cm}$ in diameter) was removed along with the trachea, thymus, and all cervical and mediastinal lymph nodes. Tracheal reconstruction was carried out by resection-anastomosis, in conjunction with tracheal release, the Dedo-Fishmann maneuver, and cervical flexion. Final diagnosis was medullary carcinoma of the thyroid pT4, pN1b. The patient was then immediately extubated, and, after 24 hours of intensive care unit stay, was returned to the hospital ward.

Six days after the operation, the patient developed a complete dehiscence of the tracheal suture, requiring emergency surgery. Due to the previous lateral devascularization, tracheal stumps appeared ischemic for about $2 \mathrm{~cm}$, resulting in an overall loss of about $9 \mathrm{~cm}$ of tracheal matter, leaving $1.5 \mathrm{~cm}$ of viable trachea above the carina and below the larynx, respectively. Tracheal continuity was reconstructed by grafting and suturing a $9 \times 6-\mathrm{cm}$ chest wall skin flap to the still viable distal and proximal tracheal stumps and, then, to the lateral esophageal margins; hence, the muscular wall of the esophagus gave 